\title{
Absence of Dystrophin Does Not Affect Myogenesis
}

\author{
Maziar Assadi ${ }^{1, *}$, Thomas Schindler ${ }^{1}$, John D. Porter $^{2}$ and Hanno Langen ${ }^{1}$ \\ ${ }^{I}$ Roche Center for Medical Genomics, F. Hoffmann-La Roche, 4070 Basel, Switzerland and ${ }^{2}$ Department of Neurology, \\ Case Western Reserve University, Cleveland, Ohio 44106, USA
}

\begin{abstract}
Duchenne muscular dystrophy (DMD) is caused by the absence of the protein dystrophin in the muscle cells. The function of dystrophin is still not clear. For enabling study of the molecular function of dystrophin, we used small inhibitory RNA (siRNA) for suppressing the expression of the protein in two muscle cell lines and achieved a quantitative knockdown. We applied two-dimensional differential gel electrophoresis (2-D DIGE) in this new in vitro model for DMD to investigate if the absence of dystrophin during myogenesis causes any changes in protein expression. We did not observe statistical relevant changes. The result of our study suggests that the absence of dystrophin does not have any effect on myogenesis.
\end{abstract}

\section{INTRODUCTION}

Duchenne muscular dystrophy (DMD) is the most common muscular dystrophy. DMD is an X-linked recessive disorder and affects 1 in 3500 male live births [1]. The disease is caused by loss-of-function mutations of the dystrophin gene which cause the lack of the dystrophin protein in DMD patients [2]. Dystrophin is a $427 \mathrm{kDa}$ protein and localises to the sarcolemma. It is still not fully understood why the absence of dystrophin triggers pathological processes in the musculature.

Although in DMD patients all muscles are deficient in dystrophin, the extraocular muscles (EOM) are spared during the entire course of the disease [3-7]. Elucidation of the mechanisms which result in the sparing of this muscle group could lead to the identification of potential therapeutic strategies.

Over the last 20 years, it has become clear that the phenotype of the EOM is at considerable variance from the skeletal muscle prototype represented by the limb and diaphragm [8-11]. For a better understanding of the properties of this muscle group, two cell lines were derived from EOM $(\mathrm{mEOM})$ and leg muscles $(\mathrm{mLM})$ of $\mathrm{C} 57 \mathrm{BL} / 6$ mouse and were used for studying the differences between these two muscle groups during the differentiation from myoblasts to myotubes [12]. In order to study the effect of absence of dystrophin in these two cell lines, we used RNA interference (RNAi) technology and were able to achieve an almost complete knockdown in the expression of dystrophin. In this new in vitro model for DMD we studied the response of diverse skeletal muscle groups to the absence of dystrophin by analyzing the protein expression changes with two-dimensional differential gel electrophoresis (2-D DIGE) technique.

*Address correspondence to this author at the Roche Center for Medical Genomics, F. Hoffmann-La Roche, 4070 Basel, Switzerland;

E-mail: maziar.assadi@ roche.com

\section{MATERIAL AND METHODS}

\section{Cell Culture}

Cell lines from EOM and leg muscles [12] were maintained in F-10 medium (Sigma) supplemented with Lglutamine (Sigma), calcium chloride, penicillin/streptomycin (Sigma) and 15\% horse serum (Sigma).

\section{Knockdown}

For the knockdown of dystrophin we used a pool of four small inhibitory RNA (siRNA) with the following sequences (5' to 3'): GGAAGAAACTCATAGATTA, GAAAGCACCTTCAGAAATA, GCAAAGAGGAGACAACTTA and GAAGAGTGTTACAGAATTA. Both cell lines were transfected at myoblast stage with $100 \mathrm{nM}$ siRNA using siLentFect lipid reagent (Bio-Rad). After four hours of incubation with siRNA-siLentFect complexes the medium was changed and the cells were induced to form myotubes by reducing medium horse serum content to $2 \%$. As controls the cell lines were either not transfected, treated only with the transfection medium or transfected with a pool of four nontargeting siRNA (Dharmacon).

\section{Sample Preparation}

72 hours after the induction of myotube formation, cells were washed three times with PBS, harvested and solubilized with lysis buffer (7 M urea, $2 \mathrm{M}$ thiourea, 4\% CHAPS, $0.3 \%$ Tris ph 8.5). Lysates were centrifuged for 15 minutes at $15,000 \mathrm{x} \mathrm{g}$ and the supernatants were transferred to a fresh tube. For further analyses protein concentration in all samples were measured and adjusted to $5 \mathrm{mg} / \mathrm{ml}$ with lysis buffer.

\section{Western Blot}

Level of dystrophin in the samples was checked with Western blot. For the detection of dystrophin, a mouse monoclonal antibody against the rod domain of the protein 
was used (Novocastra). For checking the sample load, we used a mouse monoclonal antibody against beta-actin (Sigma). Western blots were developed with HRP conjugated goat anti-mouse IgG antibody (SBA).

\section{Preparative Gels}

In addition to the 2-D DIGE gels two preparative gels were prepared with $500 \mu \mathrm{g}$ of each control sample (mEOMcontrol, mLM-control) and run under the same conditions as described above. After separation proteins were visualized with Coomassie blue staining (Invitrogen) and spots were excised with an in-house spot picker. The gel pieces were sequentially washed in water, $20 \mathrm{mM}$ Tris- $\mathrm{HCl}(\mathrm{pH} 8), 20$ $\mathrm{mM}$ Tris- $\mathrm{HCl}(\mathrm{pH} 8) / 50 \%$ acetonitrile and finally $100 \%$ acetonitrile and were then dried. The dried gel pieces were incubated in $10 \mu \mathrm{l}$ trypsin solution $(12.5 \mathrm{ng} / \mu \mathrm{l}$ in $20 \mathrm{mM}$ Tris$\mathrm{HCl} \mathrm{pH8)} \mathrm{for} 16 \mathrm{~h}$ at $37^{\circ} \mathrm{C}$. Mass analysis of peptide mixtures was performed using a Voyager-DE STR MALDI-TOF mass spectrometer (Applied Biosystems). Mass fingerprints were searched against the in-house MouseGP database using the SEQUEST software (Thermo Electronics). MouseGP is derived by assembling in sequences the results of Blast searches against the mouse chromosomes of a non-redundant protein set from Swissprot and Trembl. Search parameters included differential mass modification to methionine due to possible oxidation and static mass modification to cysteine due to alkylation by iodoacetamide. Furthermore, one missed cleavage of trypsin was accepted. Peptides identified by SEQUEST may have three different charge states $(+1,+2$, or +3 ), each of which results in a unique spectrum for the same peptide. Except in rare instances, an accepted SEQUEST result had to have a $\Delta \mathrm{Cn}$ score of at least 0.1 (regardless of charge state). Peptides with a +1 charge state were accepted if they were fully tryptic or the C-terminus of a protein and had a cross correlation (Xcorr) of at least 1.8. Peptides with a +2 charge state were accepted if they were fully tryptic or partially tryptic between the Xcorr ranges of at least 2.3 and higher. Finally, +3 peptides were only accepted if they were fully or partially tryptic and had an Xcorr $>2.8$. Only proteins identified with at least 2 different peptides, with a pepcount (number of identified peptides) larger than 7 were taken into account.

\section{2-D DIGE}

Samples were labelled with Cy2, Cy3 and Cy5 according to the manufacturer's instructions (Amersham Biosciences). Cy2 was used to label a pooled internal standard which consists of equal amount of the two control samples with nontargeting siRNA (mEOM-control, mLM-control) and the two knockdown samples with dystrophin siRNA (mEOMsiRNA, mLM-siRNA). Four different combinations were mixed and $50 \mu \mathrm{g}$ proteins per dye were loaded on one gel. Each combination was run in duplicate. The mixtures were loaded on IPG strips pH 3-11 non-linear (Amersham Biosciences). Isoelectric focusing was carried out overnight and the IPG strips were then loaded on 10\% acyrlamide SDSPAGE gels. After separation proteins were visualized using the Typhoon 9410 imager (Amersham Biosciences). Gel analysis was performed using DeCyder V 4.0 software (Amersham Biosciences).

\section{RESULTS}

As shown in Fig. (1), there is no dystrophin expression in both cell lines at myoblast stage. Detectable levels of dystrophin are found 24 hours after the induction of myogenesis. Maximum level for expression of dystrophin is reached 72 hours after the induction.
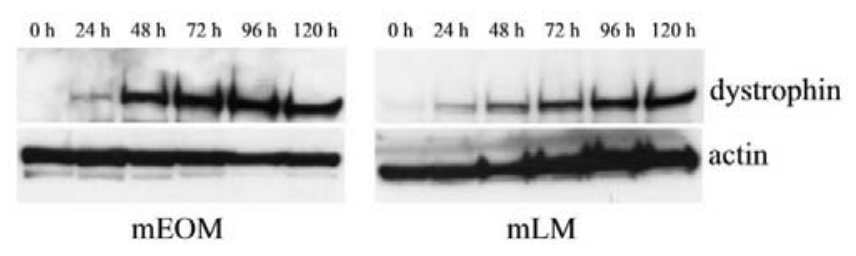

Fig. (1). Time course of dystrophin expression in mEOM and mLM cell lines. At myoblast stage $(0 \mathrm{~h})$, muscle cells do not express dystrophin. The induction for forming myotubes triggers an increase of the level of dystrophin and the maximum is reached after $72 \mathrm{~h}$. The lower panel shows the actin expression level in each sample as control for the sample load.

The levels of dystrophin in siRNA treated cells are shown in Fig. (2) at 72 hours after the transfection with siRNA. Three different controls were applied: untreated cells, cells treated with transfection medium and cells transfected with non-targeting siRNA. In all controls dystrophin is expressed at the same level. Cells treated with siRNA against dystrophin show an almost complete absence of the protein. The knockdown of dystrophin is reproducible as shown in two independent experiments in both cell lines.

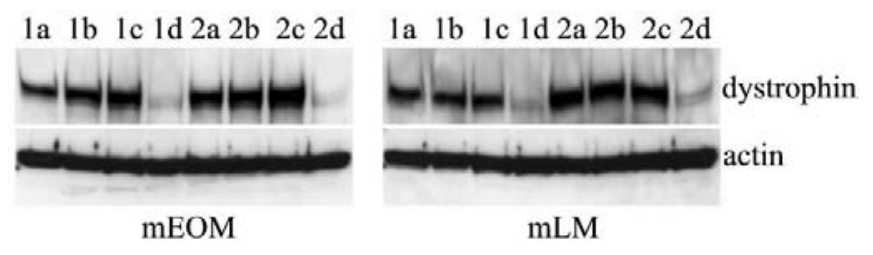

Fig. (2). Levels of dystrophin in mEOM and mLM cell lines $72 \mathrm{~h}$ after the induction of myoblasts to form myotubes. In both cell lines the expression of dystrophin was suppressed using siRNA in two independent experiments (1d, 2d). Following controls were used: untreated cells $(1 \mathrm{a}, 2 \mathrm{a})$, cells treated with transfection medium (1b, 2b) and cells transfected with non-targeting siRNA (1c, 2c).

Preparative gels were prepared for checking if there are any gross differences between the protein expression patterns of the $\mathrm{mLM}$ and $\mathrm{mEOM}$ cell lines. For this puropse 500 ug proteins of each cell line were loaded per gel and gels were stained with Commassie blue. As shown in Fig. (3), the protein expression patterns of the two cell lines look similar. Gels were further processed for mass spectrometric analysis and about 600 proteins were identified including cytoskletal proteins like actin or myosin (data not shown). The list of identified proteins of the $\mathrm{mLM}$ and $\mathrm{mEOM}$ cell line did not differ.

Fig. (4) shows the set-up for the 2D-DIGE experiment. As indicated, four different samples were obtained: two from cells incubated with non-targeting siRNA (mEOM-control, mLM-control) and two from cells incubated with dystrophin siRNA (mEOM-siRNA, mLM-siRNA). The internal standard 


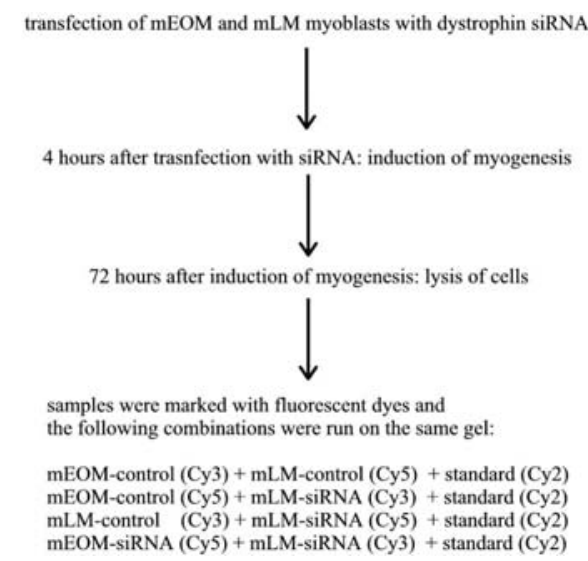

Fig. (3). Preparative gels of mEOM and mLM cell line stained with Coomassie blue. $500 \mu \mathrm{g}$ proteins were loaded per gel.

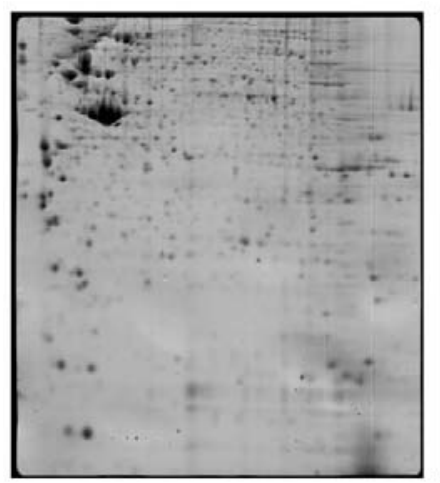

mEOM

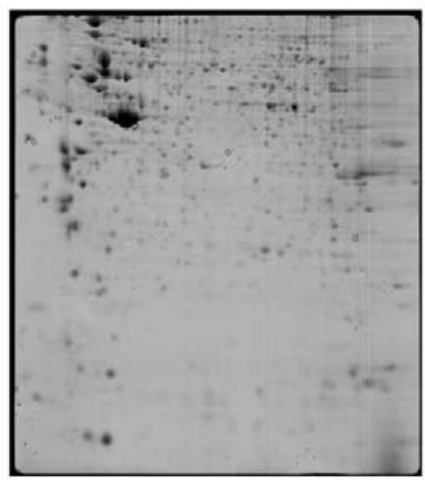

$\mathrm{mLM}$
Fig. (4). Scheme of the experimental set-up. Protein concentration in all samples was equalised to $5 \mathrm{mg} / \mathrm{ml}$ before combining them and each combination was run in duplicate. The internal standard was labelled with $\mathrm{Cy} 2$ and consists of equal amount of the two control samples with non-targeting siRNA (mEOM-control, mLM-control) and the two knockdown samples with dystrophin siRNA (mEOMsiRNA, mLM-siRNA). $50 \mu$ g proteins per dye were loaded on one gel.

consists of equal amounts of the four samples and is used to normalize protein abundance measurements across multiple gels in the experiment. Based on the results of the preparative gel, we assumed that without the knockdown of dystrophin the protein expression pattern of the two cell lines should not differ. To check this assumption, we compared the control samples of the two cell lines (mEOM-control versus mLM-control). As next we tried to find out if the knockdown of dystrophin causes any changes in the same cell line (mEOM-control versus mEOM-siRNA and mLmcontrol versus mLM-siRNA) or if the two cell lines show a different response to the absence of dystrophin (mEOMsiRNA versus mLM-siRNA). We could not find any statisti- cal significant changes in all the described comparisons (data not shown).

Control cells and cells treated with siRNA against dystrophin were kept for 10 days in culture. We did not find any obvious morphological differences between control and dystrophin knockdown myotubes (data not shown). We also checked the levels of dystrophin in both cell lines 10 days after the transfection with siRNA. As shown in Fig. (5), the level of dystrophin in cells treated with siRNA is still negligible compared to the controls.

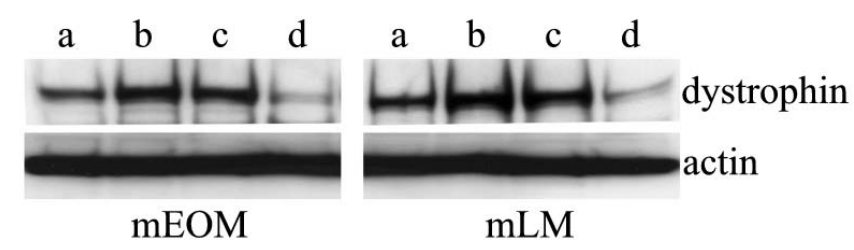

Fig. (5). Levels of dystrophin in mEOM and mLM cell lines 10 days after the induction of myoblasts to form myotubes. By using siRNA, the suppression of dystrophin expression persists in both cell lines (d). The same controls as in figure 2 were used: untreated cells (a), cells treated with transfection medium (b) and cells transfected with non-targeting siRNA (c).

\section{DISCUSSION}

In this study, we established a new in vitro model for studying the effect of dystrophin deficiency in muscle cells. This was achieved by transfecting myoblasts with siRNA against dystrophin. At the myoblast stage muscle cells do not synthesize dystrophin. This protein becomes highly expressed during myogenesis[13,14]. We used specific siRNA to apply a dystrophin knockdown prior to the expression of the protein because knockdown after the myoblast stage would be complicated by protein half life. Thereby, myogenic events can be studied in muscle cells that were devoid of dystrophin. The described model system offers two advantages for this purpose. First, working with cell culture instead of a whole muscle approach excludes external influences on the muscle cells like the extracellular matrix, innervation or contraction. Therefore, the knockdown of dystrophin in muscle cell lines should allow to study the primary reaction of muscle cells to the lack of dystrophin and if the lack of dystrophin can impair cellular function(s) per se. Second, in the model system described here, the risk of misinterpretations of experimental results due to the variability of the cell culture system is reduced to a minimum, as control experiments can be performed with the same cell line. There is great variability between independently derived cell lines, even if they originate from the same mouse strain. This should especially be considered if the cell lines are used for studying cellular functions on a molecular level.

A limitation of comparative analysis of protein samples with conventional 2-D gel electrophoresis is the high degree of gel-to-gel variation in spot patterns that makes it difficult to distinguish any true biological variation from experimental variation. To circumvent this problem we used the 2-D DIGE technique $[15,16]$. This method allowed us to run dif- 
ferent samples on the same gel for quantifying protein changes between them. We compared samples from mEOM and $\mathrm{mLM}$ cell line 72 hours after the induction of myogenesis. This time point was chosen because at this stage of myogenesis the maximum level of dystrophin expression is reached.

DMD is a relentless disorder for which there is no effective therapy. Although in patients with DMD dystrophin is deficient in all the muscles, the EOM remain unaffected during the whole course of the disease [3-7]. The compensatory or adaptive changes which result in the sparing of this muscle group have not been definitively identified. Prior studies have only excluded potential mechanisms which were hypothesized to allow the EOM to escape the devastating consequences of dystrophin deficiency $[17,18]$. We hypothesised that changes on the protein level could explain the different response of the EOM to the lack of dystrophin. To be able to distinguish any true biological variation from experimental variation, we tried to minimize any technical influences (i.e. cell culture, 2-D gel electrophoresis) in our experimental set-up. Although the knockdown of dystrophin with siRNA results in an almost complete ablation of the expression of dystrophin, we could not detect any statistically relevant changes of the protein expression pattern between the mEOM and mLM cell line. We also did not observe any obvious deleterious effect on the differentiation of myoblasts into myotubes. It seems that in vitro the absence of dystrophin does not have any gross effect on the early stages of myogenesis. This finding is consistent with in vivo situation where muscle cells remain unaffected by dystrophin deficiency until after muscle groups become functional.

There are four possible explanations why we did not find in our experiment any effect of the knockdown of dystrophin. First, siRNA experiments are limited by the fact that it is not possible to achieve a $100 \%$ absence of the targeted protein. Therefore, in cases in which the knockdown is not accompanied with the expected phenotype it can always be argued that the remaining expression of the targeted protein is sufficient to maintain normal cellular function. In our study we achieved an almost complete knockdown of dystrophin. From our point of view it is hard to believe that this negligible amount of dystrophin could be sufficient to preserve normal myogenesis if dystrophin would be essential for this process. Second, it could be that the absence of dystrophin may cause protein changes at another stage of myogenesis then the one which was investigated. In our study we compared the two cell lines 72 hours after the induction of myogenesis and could therefore have missed changes at earlier or later stages of myogenesis. This is less likely because the knockdown of dystrophin did not show any obvious effect on the morphology of the cells over the whole course of myogenesis and the level of dystrophin was still negligible 10 days after the induction of myotube formation. Third, the absence of dystrophin could cause protein changes of less abundant or membrane proteins. In this case the 2-D gel electrophoresis approach would not be the accurate method for detecting these changes. Our data do not enable us to exclude this possibility. Fourth, the lack of dystrophin does not affect cellular functions per se and other influences are needed for the development of DMD phenotype. As our experimental set-up allowed us to exclude external factors which affect muscle cells in the in vivo situation (e.g. extracellular matrix, innervation, contraction), it is likely that one or a combination of these factors triggers the DMD phenotype. Further studies are necessary to confirm this hypothesis and to investigate how these factors contribute to the accruement of DMD.

\section{REFERENCES}

[1] Worton, R. Muscular dystrophies: Diseases of the dystrophinglycoprotein complex. Science, 1995, 270(5237), 755-756.

[2] Hoffman, E.P.; Brown, R.H. Jr.; Kunkel, L.M. Dystrophin: the protein product of the Duchenne muscular dystrophy locus. Cell, 1987, 51(6), 919-928.

[3] Kaminski, H.J.; al-Hakim, M.; Leigh, R.J.; Katirji, M.B.; Ruff, R.L. Extraocular muscles are spared in advanced Duchenne dystrophy. Ann. Neurol., 1992, 32(4), 586-588.

[4] Karpati, G.; Carpenter, S. Small-caliber skeletal muscle fibers do not suffer deleterious consequences of dystrophic gene experession. Am. J. Med. Genet., 1986, 25(4), 653-658.

[5] Karpati, G.; Carpenter, S.; Prescott, S. Small-caliber skeletal muscle fibers do not suffer necrosis in mdx mouse dystrophy. Muscle Nerve, 1988, 11(8), 795-803.

[6] Khurana, T.S.; Prendergast, R.A.; Alameddine, H.S.; Tome, F.M.; Fardeau, M.; Arahata, K.; Sugita, H.; Kunkel, L.M. Absence of extraocular muscle pathology in Duchenne's muscular dystrophy: role for calcium homeostasis in extraocular muscle sparing. J. Exp. Med., 1995, 182(2), 467-475.

[7] Ragusa, R.J.; Chow, C.K.; St Clair, D.K.; Porter, J.D. Extraocular, limb and diaphragm muscle group-specific antioxidant enzyme activity patterns in control and mdx mice. J. Neurol. Sci., 1996, 139(2), 180-186.

[8] Couly, G.F.; Coltey, P.M.; Le Douarin, N.M. The development fate of the cephalic mesoderm in quail-chick chimeras. Development, 1992, 114(1), 1-15.

[9] Noden, D.M. Cell movements and control of patterned tissue assembly during craniofacial development. J. Craniofac. Genet. Dev. Biol., 1991, 11(4), 192-213.

[10] Oda, K. Motor innervation and acetylcholine receptor distribution of human extraocular muscle fibres. J. Neurol. Sci., 1986, 74(2-3), 125-133.

[11] Spencer, R.F.; Porter, J.D. Structural organization of the extraocular muscles. Rev. Oculomot. Res., 1988, 2, 33-79.

[12] Porter, J.D; Israel, S.; Gong, B.; Merriam, A.P.; Feuerman, J.; Khanna, S.; Kaminski, H.J. Distinctive morphological and gene/protein expression signatures during myogenesis in novel cell lines from extraocular and hindlimb muscle. Physiol. Genomics, 2006, 24(3), 264-275.

[13] Miranda, A.F.; Bonilla, E.; Martucci, G.; Moraes, C.T.; Hays, A.P.; Dimauro, S. Immunocytochemical study of dystrophin in muscle cultures from patients with Duchenne muscular dystrophy and unaffected control patients. Am. J. Pathol., 1988, 132(3), 410-416.

[14] Park-Matsumoto, Y.C.; Kameda, N.; Kobayashi, T.; Tsukagoshi, H. Development study of the expression of dystrophin in cultured human muscle aneurally and innervated with fetal rat spinal cord. Brain Res., 1991, 565(2), 280-289.

[15] Alban, A.; David, S.O.; Bjorkesten, L.; Andersson, C.; Sloge, E.; Lewis, S.; Currie, I. A novel experimental design for comperative two-dimensional gel analysis: two-dimensional gel electrophoresis incorporating a pooled internal standard. Proteomics, 2003, 3(1), 36-44.

[16] Shaw, J.; Rowlinson, R.; Nickson, J.; Stone, T.; Sweet, A.; Williams, K.; Tonge, R. Evaluation of saturation labelling twodimensional gel electrophoresis fluorescent dyes. Proteomics, 2003, 3(7), 1181-1195.

[17] Porter, J.D.; Merriam, A.P.; Khanna, S.; Andrade, F.H.; Richmonds, C.R.; Leahy, P.; Cheng, G.; Karathanasis, P.; Zhou, X.; Kusner, L.L.; Adams, M.E.; Willem, M.; Mayer, U.; Kaminski, 
H.J. Constitutive properties, not molecular adaptations, mediate extraocular muscle sparing in dystrophic $\mathrm{mdx}$ mice. FASEB J., 2003, 17(8), 893-895.
[18] Porter, J.D.; Merriam, A.P.; Leahy, P.; Gong, B.; Khanna, S. Dissection of temporal gene expression signatures of affected and spared muscle groups in dystrophin-deficient (mdx) mice. Hum. Mol. Genet., 2003, 12(15), 1813-1821.

(C) Assadi et al.; Licensee Bentham Open.

This is an open access article licensed under the terms of the Creative Commons Attribution Non-Commercial License (http://creativecommons.org/licenses/ by-nc/3.0/) which permits unrestricted, non-commercial use, distribution and reproduction in any medium, provided the work is properly cited. 